\title{
A Bibliometric Analysis Of Global Research Pattern On Psychological Well-
} Being

\author{
Errna Nadhirah Kamalulil*, Siti Aisyah Panatik \\ School of Human Resource Development and Psychology, Faculty of Social Sciences and Humanities, Universiti Teknologi Malaysia, 81310 UTM Johor \\ Bahru, Johor, Malaysia \\ *Corresponding author: errnanadhirah@graduate.utm.my
}

Article history: Received: 11 January 2020 Received in revised form: 28 June 2020 Accepted: 10 May 2021 Published online: 09 August 2021

\begin{abstract}
This paper reports an analysis of publications of scholars around the world in psychological well-being in the subject area of psychology. The study uses a bibliometric approach that explores patterns in global psychological well-being research, published from 1962 to 2018 . The research patterns are focused on outputs of publications, co-authorships among authors and affiliated countries as well as co-occurrences of author keywords. 928 bibliographic records were retrieved from Scopus database. The findings illustrate global researchers have significantly enhanced their impact, particularly since the period of 2007 onwards. $63 \%$ of the total global publications is published by scholars from the United States, Australia and the United Kingdom, followed by the other 63 countries/territories. Besides, top 10 productive universities were from the first three leading countries and nine of it were amongst the top 100 universities in the world. This study indicates that global scholars have made significant contributions to global psychological well-being study.
\end{abstract}

Keywords: psychological well-being, bibliometric analysis, Scopus database, VOS viewer, publication output, co-authorships, affiliated countries and cooccurrences of author keywords

(C) 2021 Penerbit UTM Press. All rights reserved

\subsection{INTRODUCTION}

Psychological well-being is conceptualized differently by various scholars according to their field or discipline of study. Many scholars argue that psychological well-being represents overall psychological quality of life in the psychology field (Ryan \& Deci, 2001). Psychological well-being is interpreted as a state of well-being in which individuals understand their own capabilities of adapting with life stresses, working productively and contributing to society (WHO, 2011, as cited in, Galderisi et al., 2015).

Previous studies conceptualize psychological well-being as the self-acceptance, autonomy, personal growth, environmental mastery and development, positive relations with others and purpose or meaning of life (Ghasempour et al., 2013; Panahi, 2016). The diverse significance of psychological well-being on both aspects of individual and organizational require further and wider study and analysis. Such study will be very valuable as it will act as guideline not only to scholars, but also to psychiatrists, psychologists and even those in the field of psychology to determine the linkages of psychological well-being and needs of people.

Bibliometric and scientometric studies on psychological well-being have been conducted to determine the general trends in this context in general (Qasim, 2017; Ryff, 2018; Sánchez-García et al., 2018). Despite this, no literature reviews were identified for bibliometric or scientometric analysis of publications that related to psychological well-being.

Prior to this, research was aimed at addressing this gap by mapping the literature on psychological well-being. For this reason, the main purpose of this study aims to accomplish the following objectives:

a) Investigate the publication output and growth of psychological well-being research area.

b) Identify the top productive journals on psychological well-being research area.

c) Identify the top countries, leading institutions and international collaboration that contribute the publications of psychological wellbeing.

d) Determine the top prolific authors and author keywords used in publications.

\subsection{METHODOLOGY}

The main research method implemented is bibliometric analysis, which plays a significant role in research performance in various fields (Reuters, 2008). This research method differentiate a bibliometric analysis paper from reviewed papers in systematic literature review (Fanaj, 2014; Murray et al., 2016; Wang et al., 2010) which mainly aims to analyze the recent research performance which could lead to a foundation of further study from other scholars on the focused variable 
Data Source and Search Strategy

This paper presents the analysis and evaluation of scientific research and publications pertaining to psychological well-being between 1962 and 2018. In 21 December 2019, data mining was obtained through Scopus database. The central theme for this bibliometric paper was research studies that consist of "psychological well*being" in the title and abstract. The steps as shown in Table 1 is performed for this bibliometric study to retrieve the research studies on psychological well-being in the field of psychology.

Table 1 The search strategies and query strings used in Scopus database

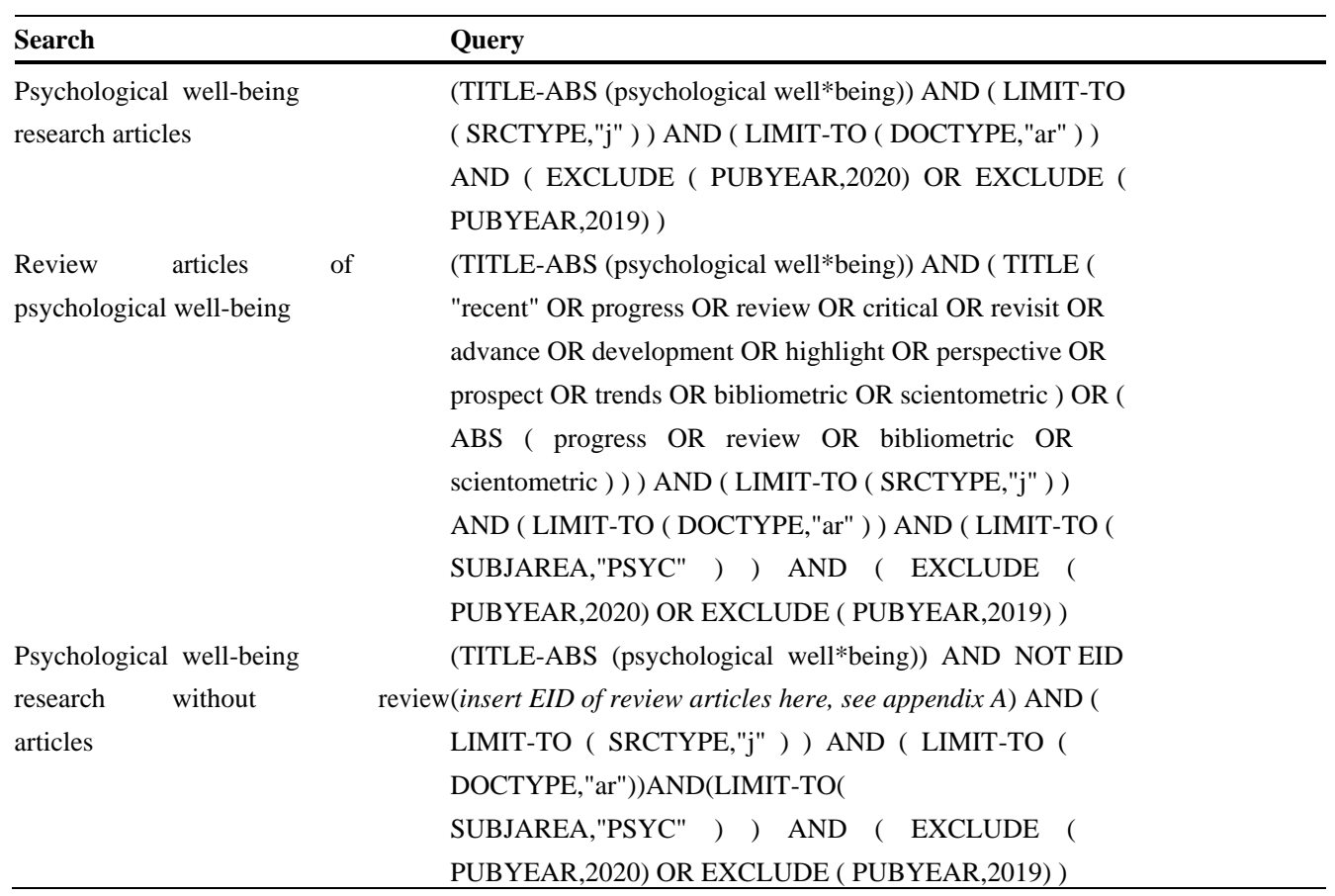

The total number of articles retrieved by using a wider search through Scopus database by "psychological well*being" in the Title and Abstract was 5147. In the screening process, the research studies by the year of publications between 1967 to 2018 was included and only selected the publications that focused on articles (document type, journals (source type) and psychology (subject area). In order to remove the irrelevant research studies, the review articles were excluded with a total of 124 publications. These criteria lead to a 928 finalized research articles that were used for bibliometric purposes. The data collection of publications on psychological well-being is showed in Figure 1.

\begin{tabular}{|c|}
\hline Identification \\
Broad search through Scopus database by "psychological well*being" in the Title and Abstract \\
Included publication year: 1967-2018, Document type: Articles, Source type: Journals and Subject area: \\
Psychology and excluded 124 review articles \\
$\mathrm{N}=928$ \\
\hline Included \\
Finalized research articles \\
$\mathrm{N}=928$
\end{tabular}

Figure 1 Flowchart of data collection of psychological well-being publications in Scopus database 
Bibliometric Maps

A total of 928 articles were retrieved and the data pertaining citation, bibliographical and author keywords were exported to VOSviewer version 1.6.13. VOSviewer is a software that helps in mapping the data network and maps visualization and exploration (Van Eck \& Waltman, 2010). Items were used to create the map, visualize it and for further exploration. The items consist of focused objects such as terms, publications and researchers. There is a link between any pair of the items that relate or connect between two items. Not only that, there can be more than one link between any pair of the items which is indicated by strength. The strength link is shown in positive numerical value where the link is stronger when the value is high.

An example of strength link is the strength of link between countries for co-authorship analysis which represents the total of publications between the two affiliated countries that have co-authored. In connection with total strength of link, it reflects the overall strength of a country's co-authorship with another country. In addition, in terms of the co-occurrence analysis, the strength of link between the author keywords refers to the number of publications that have occurred together with the two keywords.

\subsection{RESULTS}

Publication Output and Development of Psychological Well-being Research Area

A total of 928 articles on psychological well-being in psychology field had been published in a period of 57 years, from 1962 to 2018 as shown in Figure 2. The first publication was from Pohlen (1967) in 1962 and there was not recorded publications until 1974. There is lack of publications on psychological well-being from year 1975 to 1985 . The publications began to increase in 1986 where there is an increase of at least one articles a year. From 2008 onwards, the publications number increased with a 20 number of publications as the minimum number. The publications were doubled in 2010 where it leads to an increase of annual publications and rise in the cumulative total publications. Hence, the total number of publications is claimed to rise continuously.

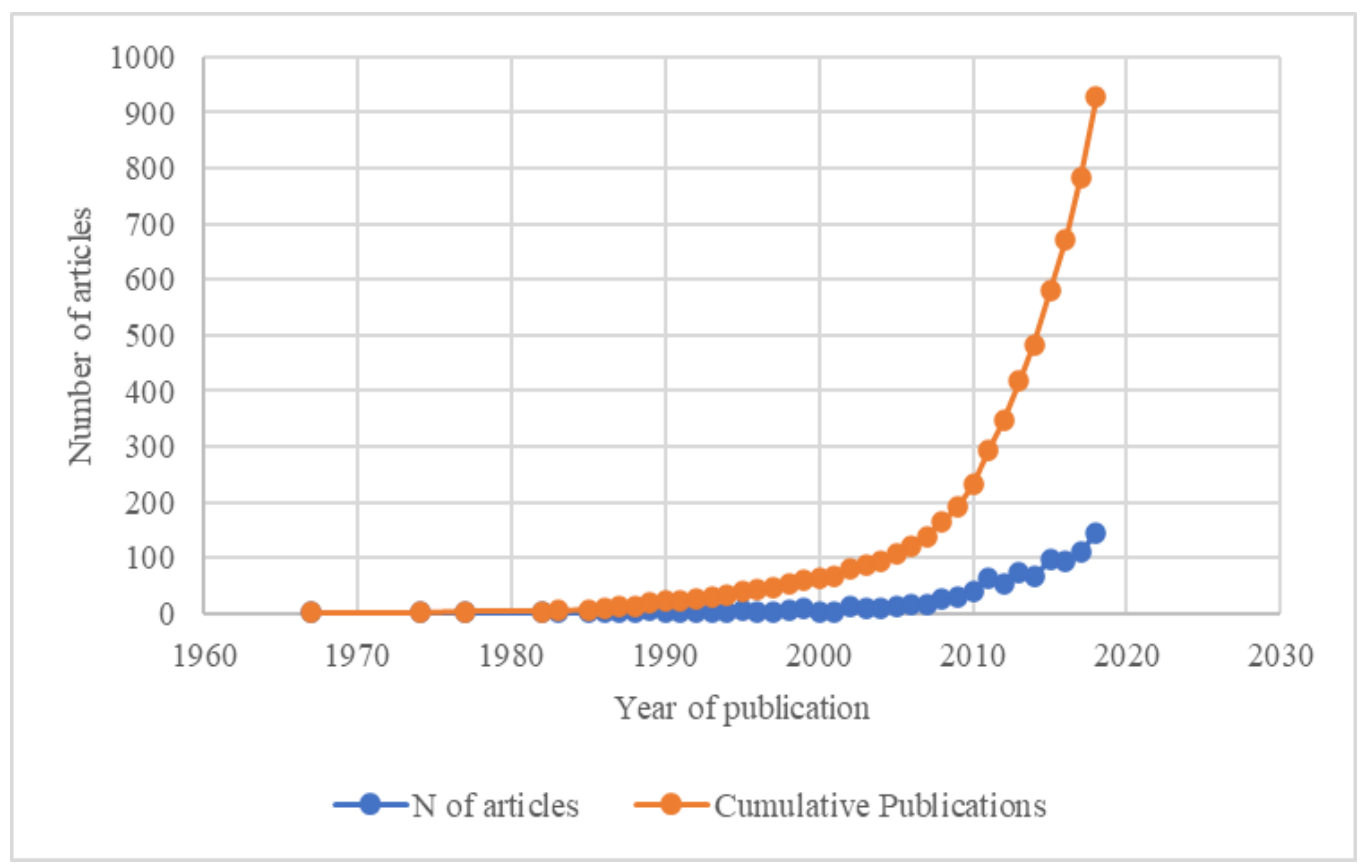

Figure 2 The annual and cumulative numbers of research articles on psychological well-being retrieved from Scopus database from year 1962 to 2018

However, out of 928 articles, only 127 articles or $16 \%$ are open access while the other 801 articles (84\%) are not freely available where payment need to be made and the subscription will allow the researcher to receive the whole article. Thus, it is suggested that the particular scholars will consider for the open access journal to ensure the other scholars and practitioners receive the required data and information and more citations will be received by the scholars from this approach.

The results also indicated that the articles published were in 13 different languages with English as the main language used by most of the scholars with the total of 855 articles $(92.1 \%)$. The second leading language was Spanish with total of 43 articles $(4.6 \%)$ followed by 11 articles (1.1\%) for French and German language respectively and 10 articles in Italian language (1.0\%). Other languages (18: 0.1\%) include Portuguese, Russian, Dutch, Greek, Macedonia, Norwegian, Serbian and Turkish. Title and abstract of the article publications must be written in English language that used other than English in order to be indexed in Scopus.

\section{Preferred Journals}

The top 10 most productive journals on psychological well-being research followed by the number of cited articles are shown in Table 2 . Seven different publishers that were the top 10 most productive journals include Cambridge University Press, Frontiers Media S. A., 
Wiley-Bleckwell, Springer Nature, Elsevier, Dietrich Steinkopff Verlag. The top three journals include Cambridge University Press, Frontiers Media S. A. and Wiley-Bleckwell. Wiley-Bleckwell appeared thrice in the top 10 most productive journals while Elsevier appeared twice.

Ageing and Society was found to be the most productive journal with 35 articles or in other words, it covers $3.8 \%$ of the total publications, followed by Frontiers in Psychology $(32 ; 3.4 \%)$, Australian Psychologist $(28 ; 3.0 \%)$ and Social Indicators Research (20; 2.2\%). The Frontiers in Psychology has the highest total citations with 13211 citations which followed by Personality and Individual Differences with 5433 total citations. In terms of the most cited articles, the Cambridge University Press that published an article by Bromley et al. (2004) has the highest cited article with 224 citations and the second most cited article with 174 citations is from Fergusson et al. (2013) and Frontiers Media S.A. as the publisher.

Based on the CiteScore 2018 report, only one journal had a CiteScore of 3 and above that was Social Psychiatry and Psychiatric Epidemiology (3.29) even though it ranked $8^{\text {th }}$ with 13 publications in Scopus. Total journals that have CitesScore of 2 and above was five that include Ageing and Society, Frontiers in Psychology, Social Indicators Research, Children and Youth Services Review and Personality and Individual Differences. The lowest CiteScore was the Australian Psychologist (1.24) which ranked $3^{\text {rd }}$ in the top most productive journals which might be due to not freely available to access the articles published, leading to low CiteScore.

Table 2 The top 10 most productive journals on psychological well-being research with their cited articles

\begin{tabular}{|c|c|c|c|c|c|c|c|}
\hline Rank & Journal & $\begin{array}{l}\text { TP } \\
(\%)\end{array}$ & TC & $\begin{array}{l}\text { CiteScore } \\
2018\end{array}$ & The most cited article (reference) & $\begin{array}{l}\text { Times } \\
\text { cited }\end{array}$ & Publisher \\
\hline 1 & $\begin{array}{l}\text { Ageing and } \\
\text { Society }\end{array}$ & $\begin{array}{c}35 \\
(3.8)\end{array}$ & 617 & 2.22 & $\begin{array}{l}\text { Mothers supporting children with autistic } \\
\text { spectrum disorders: Social support, mental } \\
\text { health status and satisfaction with services } \\
\text { (Bromley et al., 2004). }\end{array}$ & 224 & $\begin{array}{l}\text { Cambridge } \\
\text { University } \\
\text { Press }\end{array}$ \\
\hline 2 & $\begin{array}{l}\text { Frontiers in } \\
\text { Psychology }\end{array}$ & $\begin{array}{c}32 \\
(3.4)\end{array}$ & 13211 & 2.40 & $\begin{array}{l}\text { Childhood sexual abuse and adult } \\
\text { developmental outcomes: Findings from a } \\
\text { 30-year longitudinal study in New Zealand } \\
\text { (Fergusson } \text { et al., 2013). }\end{array}$ & 174 & $\begin{array}{l}\text { Frontiers Media } \\
\text { S.A. }\end{array}$ \\
\hline 3 & $\begin{array}{l}\text { Australian } \\
\text { Psychologist }\end{array}$ & $\begin{array}{c}28 \\
(3.0)\end{array}$ & 224 & 1.24 & $\begin{array}{l}\text { Interpreting the WHOQOL-Brèf: Preliminary } \\
\text { population norms and effect sizes } \\
\text { (Hawthorne et al., 2006). }\end{array}$ & 127 & $\begin{array}{l}\text { Wiley- } \\
\text { Bleckwell }\end{array}$ \\
\hline 4 & $\begin{array}{l}\text { Social } \\
\text { Indicators } \\
\text { Research }\end{array}$ & $\begin{array}{c}20 \\
(2.2)\end{array}$ & 1834 & 2.15 & $\begin{array}{l}\text { Predictors of vulnerability to reduced body } \\
\text { image satisfaction and psychological } \\
\text { wellbeing in response to exposure to } \\
\text { idealized female media images in adolescent } \\
\text { girls (Durkin \& Paxton, 2002). }\end{array}$ & 128 & Springer Nature \\
\hline 5 & $\begin{array}{l}\text { International } \\
\text { Journal of } \\
\text { Psychology }\end{array}$ & $\begin{array}{c}18 \\
(1.9)\end{array}$ & 365 & 1.86 & $\begin{array}{l}\text { Improving classroom learning environments } \\
\text { by cultivating awareness and resilience in } \\
\text { education (CARE): Results of a randomized } \\
\text { controlled trial (Jennings et al., 2013). }\end{array}$ & 93 & $\begin{array}{l}\text { Wiley- } \\
\text { Bleckwell }\end{array}$ \\
\hline 6 & $\begin{array}{l}\text { Australian } \\
\text { Journal of } \\
\text { Psychology }\end{array}$ & $\begin{array}{c}15 \\
(1.6)\end{array}$ & 123 & 1.35 & $\begin{array}{l}\text { Stigma, social support, and depression } \\
\text { among people living with HIV in Thailand } \\
\text { (Li et al., 2009). }\end{array}$ & 116 & $\begin{array}{l}\text { Wiley- } \\
\text { Bleckwell }\end{array}$ \\
\hline 7 & $\begin{array}{l}\text { Children and } \\
\text { Youth } \\
\text { Services } \\
\text { Review }\end{array}$ & $\begin{array}{c}14 \\
(1.5)\end{array}$ & 1950 & 2.04 & $\begin{array}{l}\text { 'I like to go out to be energised by different } \\
\text { people': An exploratory analysis of mobility } \\
\text { and wellbeing in later life (Ziegler \& } \\
\text { Schwanen, 2011). }\end{array}$ & 109 & Elsevier \\
\hline 8 & $\begin{array}{l}\text { Social } \\
\text { Psychiatry } \\
\text { and } \\
\text { Psychiatric } \\
\text { Epidemiolog } \\
\text { y }\end{array}$ & $\begin{array}{c}13 \\
(1.4)\end{array}$ & 1709 & 3.29 & Institutional betrayal (Smith \& Freyd, 2014). & 76 & $\begin{array}{l}\text { Dietrich } \\
\text { Steinkopff } \\
\text { Verlag }\end{array}$ \\
\hline 9 & $\begin{array}{l}\text { Personality } \\
\text { and } \\
\text { Individual } \\
\text { Differences }\end{array}$ & $\begin{array}{c}11 \\
(1.2)\end{array}$ & 5433 & 2.65 & The varieties of wellbeing (Lawton, 1983). & 58 & Elsevier \\
\hline 10 & $\begin{array}{l}\text { Psychology } \\
\text { Health and } \\
\text { Medicine }\end{array}$ & $\begin{array}{c}11 \\
(1.2)\end{array}$ & 644 & 1.75 & $\begin{array}{l}\text { Mindfulness and self-compassion as } \\
\text { predictors of psychological wellbeing in } \\
\text { long-term meditators and matched } \\
\text { nonmeditators (Baer } \text { et al., 2012). }\end{array}$ & 81 & $\begin{array}{l}\text { Taylor } \\
\text { Francis }\end{array}$ \\
\hline
\end{tabular}

\section{Leading Countries, Top Institutions and International Collaboration}

Figure 3 displays the top 15 most productive countries that contribute to the development of global psychological well-being research publications. About $63 \%$ of the research activity worldwide was led by top three countries, United States, Australia and United Kingdom representing these three countries act as major contributor in the global growth of psychological well-being research area. United States was a leading country with 212 publications, covering $22.8 \%$ of the total global publications. Australian and United Kingdom had contributed a total of $192(20.7 \%)$ and $187(20.2 \%)$ total publications worldwide respectively. 


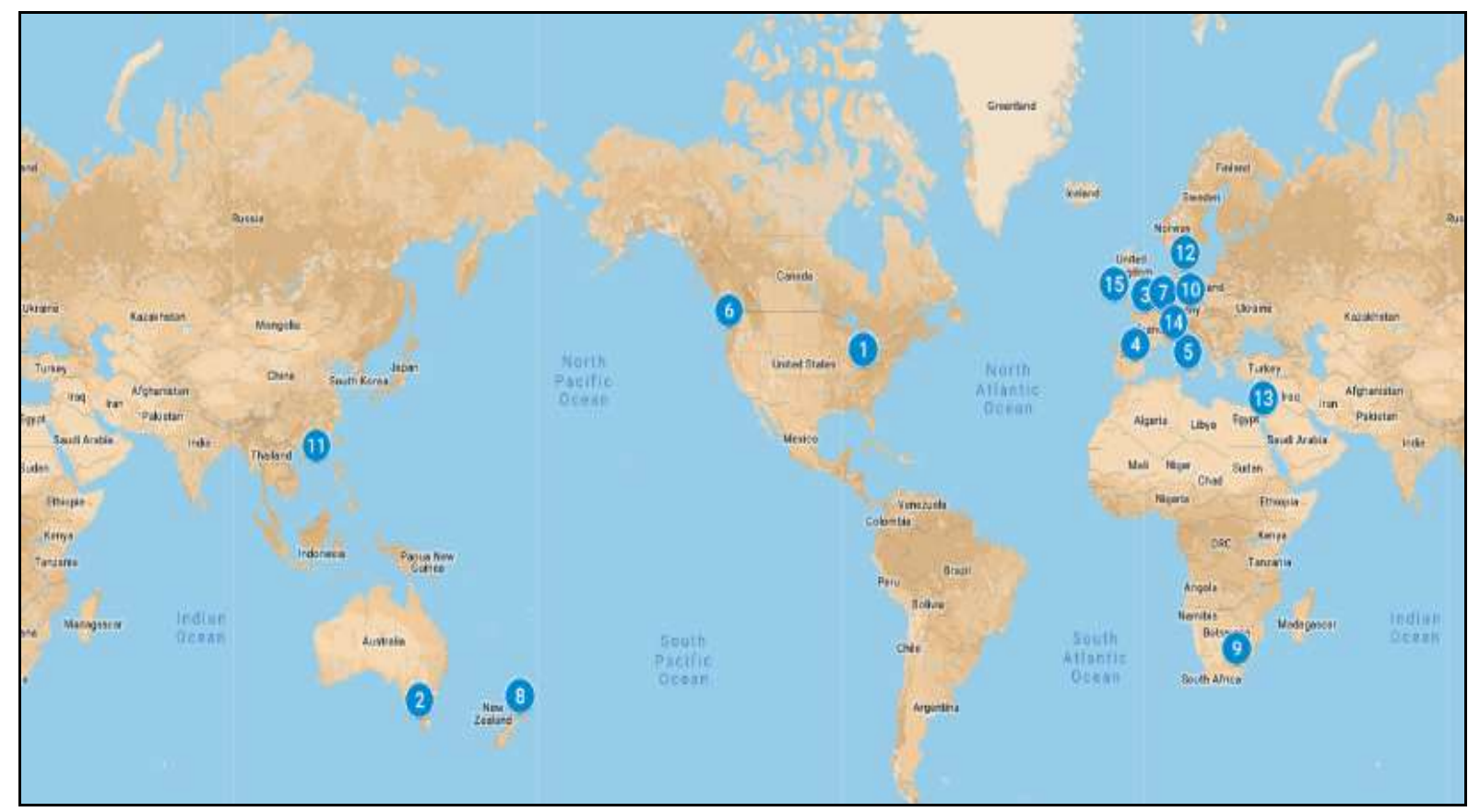

Figure 3 Fifteen leading countries in psychological well-being publications

Besides, there were also top 50 universities based on the QS Top Universities (2019) as shown in Table 3 which the leading universities were from the top three productive countries in the world. University of Michigan, Ann Arbor ranked $20^{\text {th }}$, University of Melbourne ranked $39^{\text {th }}$ and University College London ranked $10^{\text {th }}$ in the world. According to these rankings based on the top 50 universities in the world, the top three universities contribute to the most productive academic institutions with 29 total global publications by University of Melbourne, followed by 22 and 12 total global publications from University College London and University of Michigan, Ann Arbor respectively.

Table 3 The top 15 most prolific countries and academic institutions in psychological well-being publications

\begin{tabular}{|c|c|c|c|c|c|}
\hline Rank & Country & TPc & The most productive academic institution & TPi & $\begin{array}{l}\text { No. of affiliated } \\
\text { countries }\end{array}$ \\
\hline 1 & United States & 212 & University of Michigan, Ann Arbor & 12 & 36 \\
\hline 2 & Australia & 192 & University of Melbourne & 29 & 16 \\
\hline 3 & United Kingdom & 187 & University College London & 22 & 25 \\
\hline 4 & Spain & 51 & Universidad del Pais Vasco & 7 & 13 \\
\hline 5 & Italy & 47 & Universita degli Studi di Roma La Sapienza & 8 & 10 \\
\hline 6 & Canada & 43 & The University British Columbia & 6 & 16 \\
\hline 7 & Netherlands & 36 & Utrecht University & 6 & 14 \\
\hline 8 & New Zealand & 27 & University of Auckland & 8 & 6 \\
\hline 9 & South Africa & 27 & North-West University & 10 & 5 \\
\hline 10 & Germany & 19 & Humboldt-Universität zu Berlin & 3 & 12 \\
\hline 11 & China & 17 & The University of Hong Kong & 2 & 9 \\
\hline 12 & Sweden & 16 & Gothenburg University & 4 & 13 \\
\hline 13 & Israel & 15 & University of Haifa & 4 & 4 \\
\hline 14 & Switzerland & 15 & University of Zurich & 5 & 6 \\
\hline 15 & Ireland & 14 & National University of Ireland Galway & 4 & 7 \\
\hline
\end{tabular}

TPc: Total publications based on countries; TPi: Total publications based on institutions

Figure 4 indicates the countries or territories distributions per region. Based on the map, when two nations are close to each other, then their connectedness or relatedness are stronger and link strength between two countries also higher, where the line is thicker. Based on the co-authorships results, United States was the most affiliated country with 74 co-authorships that linked to 36 countries/territories. The list was then followed by countries with links between countries and co-authorships that are: (1) United Kingdom 
$(25,66)$; (2) Australia $(16,44)$; (3) Canada $(16,23)$; and (4) Italy $(14,18)$. It was also shown that only the top nine countries that were affiliated with other countries more than 10 times in publishing articles on psychological well-being.

The varied number of the total of international collaboration might be due to several factors. One of the factors could be the participation of active collaborators among countries within the larger network. The stronger the network, then the global collaboration would be higher. Not only that, it is also due to the participation of foreign students who studied in a particular academic institution that contribute to the collaboration of their respective countries. Besides, the research funding also plays key role in determining the active collaboration among countries as larger network requires more fund.

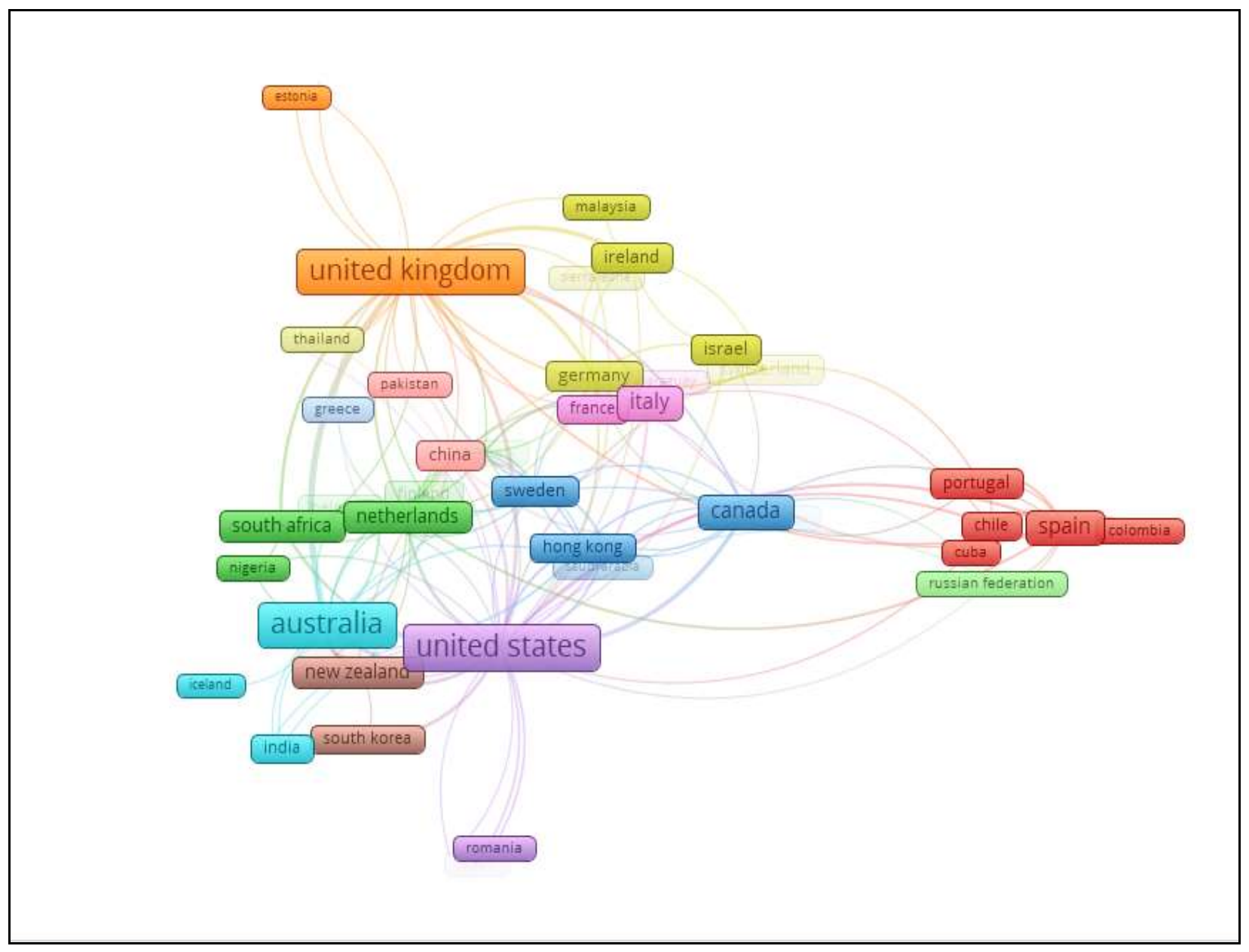

Figure 4 A bibliometric map screenshot, produced on the basis of co-authorships of affiliated countries. The following URL can be used to view Figure 4 in VOSviewer: http://bit.ly/co-authorships

\section{Leading Authors}

Table 4 indicates the 15 most prolific authors list in psychological well-being research area with total of four affiliated countries. Australia was the highest affiliated country with 11 authors, England ( 3 authors) while United States and Scotland consist of one author only. The first publications on psychological well-being was between 1974 to 2011 in which three authors had responsibilities as the first author and the other 12 authors as a co-author which these positions do not have any specific rules in the authorship order.

J. B. Brooks-Gunn from Australia was the first leading author in the list with a total record of 476 publications since year 1974 with 94 h-index and 36510 times citations. C. G. Sibley was the second top authors from England have half of the h-index from the first author that is 39 and the difference of the total citations were very huge which this author only has 6635 times citations. The other authors from England include C. Lee and L. M. Cortina ranked $6^{\text {th }}$ and $10^{\text {th }}$. The other countries other than Australia and England were United States and Scotland from P. A. Creed who ranked $11^{\text {th }}$ and L. E. Kotila who ranked $15^{\text {th }}$.

In almost all scientific fields, there has been a movement towards broader co-authorship (Casanueva \& Galán, 2006; Cronin et al., 2003). In addition, co-authorship is the most structured representation in a scientific field of intellectual collaboration. If two or more authors collaborate in research, there will not only be a greater amount of scientific outcome, but also importantly a greater quality (Hudson, 1996). The trend towards broader co-authorship of published articles is proven by psychological well-being in the field of psychology. 
Table 4 List of 15 most prolific authors in psychological well-being research area

\begin{tabular}{|c|c|c|c|c|c|c|c|c|}
\hline Rank & Author & $\begin{array}{l}\text { Scopus author } \\
\text { ID }\end{array}$ & $\begin{array}{l}\text { Year of } 1^{\text {st }} \\
\text { publication }\end{array}$ & $\mathbf{T P}$ & h-index & $\mathbf{T C}$ & Current affiliation & Country \\
\hline 1 & $\begin{array}{l}\text { Brooks- } \\
\text { Gunn, Jeanne } \\
\text { B. }\end{array}$ & 7005457863 & $1974^{\mathrm{a}}$ & 476 & 94 & 36510 & $\begin{array}{l}\text { University } \\
\text { Melbourne }\end{array}$ & Australia \\
\hline 2 & $\begin{array}{l}\text { Sibley, Chris } \\
\text { G. }\end{array}$ & 7102504126 & $2001^{\mathrm{a}}$ & 290 & 39 & 6635 & UCL & England \\
\hline 3 & $\begin{array}{l}\text { Burns, } \\
\text { Richard }\end{array}$ & 55682654356 & $2007^{b}$ & 64 & 16 & 929 & $\begin{array}{l}\text { Australian National } \\
\text { University }\end{array}$ & Australia \\
\hline 4 & Dudgeon, Pat & 6602161727 & $2000^{\mathrm{a}}$ & 32 & 10 & 328 & Deakin University & Australia \\
\hline 5 & Kendig, Hal & 6603690761 & $1976^{\mathrm{a}}$ & 136 & 26 & 2348 & Monash University & Australia \\
\hline 6 & $\begin{array}{l}\text { Lee, } \\
\text { Christina }\end{array}$ & 24463988800 & $1983^{\mathrm{a}}$ & 187 & 39 & 7731 & $\begin{array}{l}\text { King's } \quad \text { College } \\
\text { London }\end{array}$ & England \\
\hline 7 & $\begin{array}{l}\text { Waldfogel, } \\
\text { Jane }\end{array}$ & 7005529343 & $1995^{\mathrm{a}}$ & 181 & 52 & 9051 & $\begin{array}{l}\text { The University of } \\
\text { Sydney }\end{array}$ & Australia \\
\hline 8 & $\begin{array}{l}\text { Barlow, Julie } \\
\text { Helen }\end{array}$ & 7402197697 & $1988^{b}$ & 140 & 38 & 5835 & $\begin{array}{l}\text { University of } \\
\text { Queensland }\end{array}$ & Australia \\
\hline 9 & $\begin{array}{l}\text { Berry, John } \\
\text { W. }\end{array}$ & 7402634538 & $1966^{\mathrm{a}}$ & 141 & 48 & 14207 & $\begin{array}{l}\text { University of } \\
\text { Western Australia }\end{array}$ & Australia \\
\hline 10 & $\begin{array}{l}\text { Cortina, Lilia } \\
\text { M. }\end{array}$ & 6603951675 & $1998^{a}$ & 73 & 31 & 4341 & $\begin{array}{l}\text { University of } \\
\text { Manchester }\end{array}$ & England \\
\hline 11 & $\begin{array}{l}\text { Creed, Peter } \\
\text { A. }\end{array}$ & 7003468262 & $1996^{\mathrm{a}}$ & 141 & 32 & 3085 & $\begin{array}{l}\text { University } \\
\text { Michigan, of } \\
\text { Arbor }\end{array}$ & $\begin{array}{l}\text { United } \\
\text { States }\end{array}$ \\
\hline 12 & Deary, Ian J. & 57193752767 & $1982^{\mathrm{a}}$ & 1397 & 120 & 62893 & $\begin{array}{l}\text { Swinburne } \\
\text { University } \\
\text { Technology }\end{array}$ & Australia \\
\hline 13 & $\begin{array}{l}\text { Giallo, } \\
\text { Rebecca }\end{array}$ & 23097685100 & $2003^{a}$ & 105 & 23 & 1554 & La Trobe University & Australia \\
\hline 14 & $\begin{array}{l}\text { Kessels, Roy } \\
\text { P.C. }\end{array}$ & 26642874000 & $1998^{a}$ & 299 & 45 & 9147 & $\begin{array}{l}\text { Australian } \\
\text { University }\end{array}$ & Australia \\
\hline 15 & $\begin{array}{l}\text { Kotila, } \\
\text { Letitia E. }\end{array}$ & 54389393100 & $2011^{\mathrm{b}}$ & 15 & 7 & 202 & $\begin{array}{l}\text { University } \\
\text { Edinburgh }\end{array}$ & Scotland \\
\hline
\end{tabular}

\section{Author Keywords}

Keywords tend to contextualize the contents of the research article as well as to focus and develop the basic concepts of the research. For bibliometric application, Figure 5 shows the author keywords co-occurrence in psychological well-being research area in the title, abstract or even the entire research articles within or across sets of published articles. The co-occurrence distribution provides a comprehensive overview of the areas of research of psychological well-being within the psychology field over a given time period. (Qasim, 2017). 


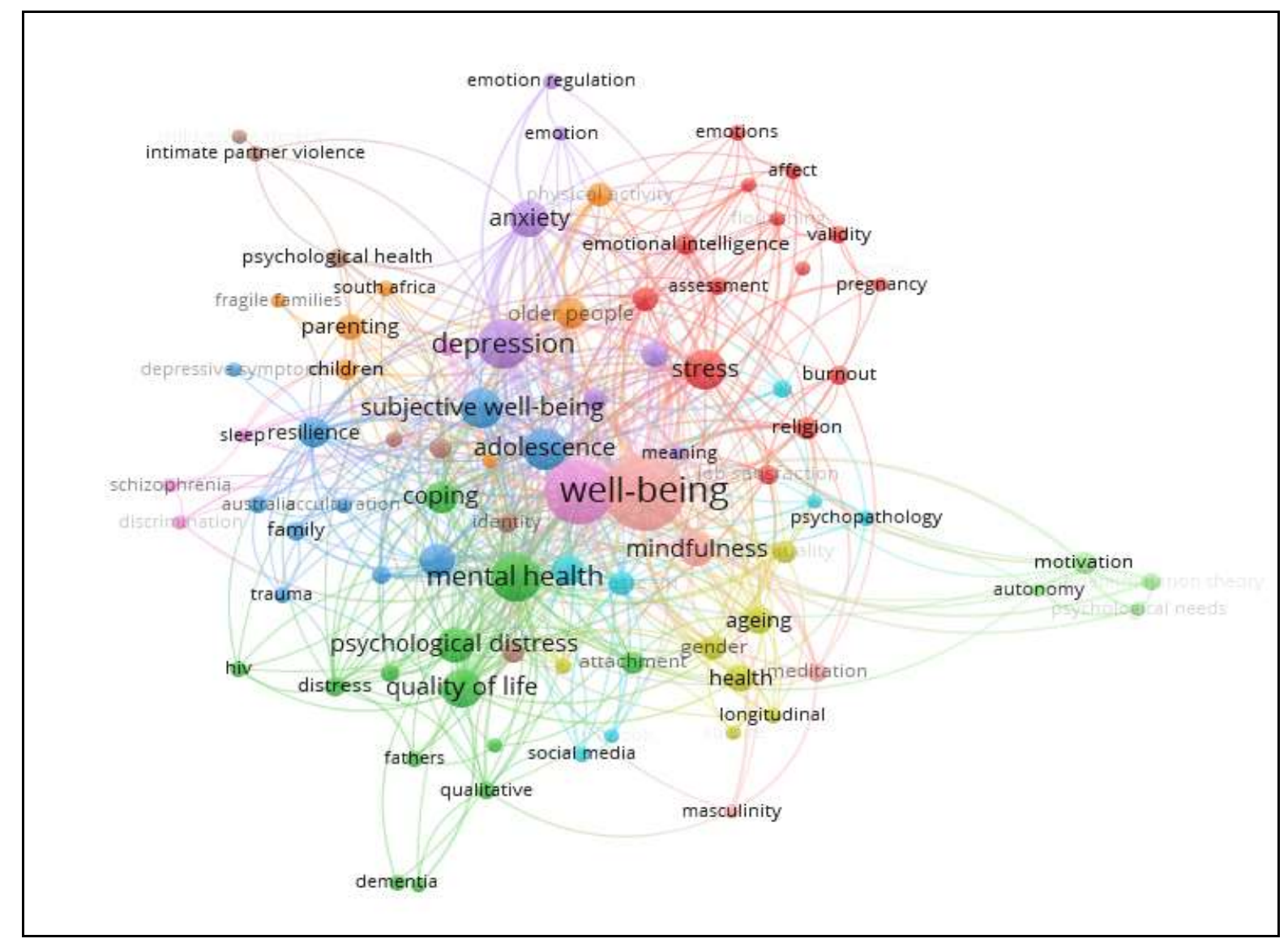

Figure 5 A bibliometric map screenshot, produced on the basis of author keywords. The following URL can be used to view Figure 5 in VOSviewer: $\underline{\text { http://bit.ly/authorkeywords }}$

The results proved that well-being in more general concept was the highest usage of keywords from various scholars with 127 occurrences and 66 links to other keywords. The second most frequent encountered keyword was psychological well-being which more specific to the focus of publications with 95 occurrences and 40 links. Besides, the keywords depression, stress and anxiety were the also amongst the highest keywords that have been used by the authors with occurrences and links of 54 and 38,36 and 25 and 30 and 25 which these keywords are the emotional aspects of well-being which in a bigger concept, mental health contributed a total of 52 occurrences and 39 links.

\section{Implication of Study}

This bibliometric analysis will provide insights for scholars from various disciplines on the trend of psychological well-being study in terms of publication growth, top productive journals, countries, institutions, international collaboration as well as prolific authors. The results represent baseline data to identify bibliometric measures in the existing studies and the global trend will act as direction to international psychology research to explore more on the least topic regarding psychological well-being that need further explanation by investigating the underlying determinants. Studies in this particular area should be extensive and therefore, this analysis will facilitate scholars to maintain the up-to-date research on psychological well-being. Consequently, effective strategies in research for all nations can be enhanced. On the other hand, through contributions of new empirical evidences, new initiatives to foster positive psychological wellbeing can be developed, particularly by health practitioners and new beneficial health policy by the government can be implemented.

\section{Limitation of Study}

The results by using the query string might not include all available research articles in Scopus database that associated with psychological well-being because the search of "psychological well*being" has been restricted within titles and abstracts only. This is due to some scholars that used different terms of psychological well-being such as psychological well being. Thus, the search string could be narrowed down to gain more related articles on psychological well-being for the further analysis of bibliometric. It is also suggested to utilize multiple databases for outputs comparison such as by using Scopus databases and Web of Science. 


\subsection{CONCLUSION}

This bibliometric analysis has presented a comprehensive overview of psychological well-being global research patterns or trends where a total of 928 publications from Scopus database have been retrieved. The movement towards the publications on this research area is increasing starting 2007 onwards and it is estimated to rise continuously as this become a significant topic or issue that being discussed by many scholars from different disciplines. It is highly recommended to increase the research funding from government grants, non-profit organizations and companies that involved in research and development to academic institutions, particularly among the universities that have psychology majors to boost the research output. United States, Australia and United Kingdom were recognized as the most productive countries in the world that contribute a huge number of publications on psychological well-being and build strong international collaborations whereas Venezuela, Uzbekistan and Ukraine were found to be the least countries in contributing to psychological well-being studies. For this reason, it is suggested that more international collaborations should be facilitated in order to emphasize psychological well-being related to psychology field, especially in countries with high research resources. In overall, this study has shown that bibliometric analysis is a good methodological technique for mapping literature on a specific topic and determining research gaps in that topic.

\section{Acknowledgement}

Thank you to the Ministry of Education (MOE) and Universiti Teknologi Malaysia for the financial support through FRGS Vot No: 5F172.

\section{References}

Baer, R., Peters, J. R., \& Lykins, E. L. (2012). Mindfulness and Self-compassion as Predictors of Psychological Wellbeing in Long-term Meditators and Nonmeditators. The Journal of Positive Psychology, 7(3), 230-238. https://doi.org/10.1080/17439760.2012.674548

Bromley, J., Hare, D. J., Davison, K., \& Emerson, E. (2004). Mothers Supporting Children with Autistic Spectrum. Autism, 8(4), 409-423, https://doi.org/10.1177/1362361304047224

Casanueva, C., \& Galán, J. L. (2006). Co-authorship in Management and Organizational Studies: An Empirical and Network Analysis. Journal Of Management Studies, 43(5), 957-983.

Cronin, B., Shaw, D., \& Barre, K. La. (2003). A Cast of Thousands : Coauthorship and Subauthorship Collaboration in the 20th Century as Manifested in the Scholarly Journal Literature of Psychology and Philosophy. Journal of the American Society for Information Science and Technology, 54(9), 855-871.

Durkin, S. J., \& Paxton, S. J. (2002). Predictors of Vulnerability to Reduce Body Image Satisfaction and Psychological Wellbeing in Response to Exposure to Idealized Female Media Images in Adolescent Girls. Journal of Psychosomatic Research, 53(5), 995-1005.

Fanaj, N. (2014). A Systematic Literature Review on Self-esteem Psychological Well-being in Kosovo. Human And Social Sciences at the Common Conference, 103-108.

Fergusson, D. M., Mcleod, G. F. H., \& Horwood, L. J. (2013). Child Abuse \& Neglect Childhood Sexual Abuse and Adult Developmental Outcomes: Findings from a 30-year Longitudinal Study in New Zealand. Child Abuse \& Neglect, 37(9), 664-674. https://doi.org/10.1016/j.chiabu.2013.03.013

Galderisi, S., Heinz, A., Kastrup, M., Beezhold, J., \& Sartorius, N. (2015). Toward a New Definition of Mental Health. World Psychiatry, 14(2), 231-233. https://doi.org/10.1002/wps.20231

Ghasempour, A., Jodat, H., Soleimani, M., \& Shabanlo, K. Z. (2013). Happiness as a Predictor of Psychological Well-being of Male Athlete Students. Annals of Applied Sport Science, 1(2), 25-32.

Hawthorne, G., Herrman, H., \& Murphy, B. (2006). Interpreting the WHOQOL-BREF: Preliminary Population Norms and Effect Sizes. Social Indicators Research, 77(1), 37-59. https://doi.org/10.1007/s11205-005-5552-1

Hudson, J. (1996). Trends in Multi-authored Papers in Economics. Journal of Economic Perspectives, 10(3), 153-158. https://doi.org/10.1257/jep.10.3.153

Jennings, P. A., Frank, J. L., Snowberg, K. E., Coccia, M. A., \& Greenberg, M. T. (2013). Improving Classroom Learning Environments by Cultivating Awareness and Resilience in Education (care): Results of a Randomized Controlled Trial. School Psychology Quarterly, 28(4), 374-390. https://doi.org/10.1037/spq0000035

Lawton, M. P. (1983). The Varieties of Wellbeing. Experimental Aging Research, 9(2), 65-72. https://doi.org/10.1080/03610738308258427

Li, L., Lee, S. J., T., P., Jiraphongsa, C., \& Rotheram-Borus, M. J. (2009). Stigma, Social Support and Depression among People Living with HIV in Thailand. AIDS Care, 21(8), 1007-1013. https://doi.org/10.1080/09540120802614358.Stigma

Murray, M., Murray, L., \& Donnelly, M. (2016). Systematic Review of interventions to Improve the Psychological Well-being of General Practitioners. BMC Family Practice, 17(1), 36. https://doi.org/10.1186/s12875-016-0431-1

Panahi, S. (2016). Predictors of psychological well-being among Malaysian graduates. The European Journal of Social and Behavioural Sciences, 16(2), 2067-2083. https://doi.org/10.15405/ejsbs.186

Pohlen, M. (1967). Über Die Beziehung Zwischen Rhythmischer Einstimmung Und Frühzeitiger Differenzierung Des Gehörsinns Bei Der Entstehung Des Ichs Und Der Sprache. Psychotherapy and Psychosomatics, 15(6), 407-445. https://doi.org/10.1159/000285907

Qasim, M. (2017). Sustainability and Wellbeing: A Scientometric and Bibliometric review of the literature: Sustainability and Wellbeing. Journal of Economic Surveys, 31(4), 1035-1061. https://doi.org/10.1111/joes.12183

QS Top Universities. (2019). QS World University Rankings: Who Rules? Retrieved from https://www.topuniversities.com/university-rankings/worlduniversity-rankings/2019 Retrieved date: 07 January 2020.

Ryan, R. M., \& Deci, E. L. (2001). On Happiness and Human Potentials: A Review Of Research on Hedonic and Eudaimonic Well-Being. Annual Review of Psychology, 52(1), 141-166.

Ryff, C. D. (2018). Well-being with Soul: Science in Pursuit of Human Potential. Perspectives on Psychological Science, 13(2), 242-248. https://doi.org/10.1177/1745691617699836

Sánchez-García, J. C., Vargas-Morúa, G., \& Hernández-Sánchez, B. R. (2018). Entrepreneurs' Well-being: A Bibliometric Review. Frontiers in Psychology, 9, 1-19. https://doi.org/10.3389/fpsyg.2018.01696

Smith, C. P., \& Freyd, J. J. (2014). Institutional Betrayal. American Psychologist, 69(6), 575-587.

van Eck, N. J., \& Waltman, L. (2010). Software Survey: VOSviewer, A Computer Program for Bibliometric Mapping. Scientometrics, 84(2), 523-538. https://doi.org/10.1007/s11192-009-0146-3

Wang, C., Bannuru, R., Ramel, J., Kupelnick, B., \& Scott, T. (2010). Tai Chi on Psychological Well-being: Systematic Review and Meta-analysis. BMC 
Complementary and Alternative Medicine, 10(23), 1-16. https://doi.org/10.1186/1472-6882-10-23

Whitepaper using Bibliometrics: A Guide to Evaluating Research Performance with Citation Data. (2008). America: Thomson Reuters.

Ziegler, F., \& Schwanen, T. I. M. (2011). 'I like to Go Out to be Energised by Different People": An Exploratory Analysis of Mobility and Wellbeing in LaterLife.' Ageing \& Society, 31(5), 758-781. https://doi.org/10.1017/S0144686X10000498

\section{APPENDIX A}

EID of review articles:

(2-s2.0-85046149773 OR 2-s2.0-85050149669 OR 2-s2.0-85041011409 OR 2-s2.0-85021233849 OR 2s2.0-85048574074 OR 2-s2.0-85051110994 OR 2-s2.0-85046814747 OR 2-s2.0-85046907025 OR 2-s2.085045312554 OR 2-s2.0-85044841041 OR 2-s2.0-85042494805 OR 2-s2.0-85044351291 OR 2-s2.085039903598 OR 2-s2.0-85042566015 OR 2-s2.0-84983474756 OR 2-s2.0-85024489519 OR 2-s2.085030675079 OR 2-s2.0-85065608957 OR 2-s2.0-84994444626 OR 2-s2.0-85069731091 OR 2-s2.085028454624 OR 2-s2.0-85046650304 OR 2-s2.0-85027973957 OR 2-s2.0-85029611829 OR 2-s2.085015256902 OR 2-s2.0-85025118422 OR 2 -s2.0-85025142297 OR 2-s2.0-85025140738 OR 2 -s2.085011387391 OR 2-s2.0-85017459057 OR 2-s2.0-85015762601 OR 2-s2.0-85012940732 OR 2-s2.085028421009 OR 2-s2.0-85026749767 OR 2-s2.0-85007409311 OR 2-s2.0-85027309915 OR 2-s2.085061232273 OR 2-s2.0-85021699149 OR 2-s2.0-84991794180 OR 2-s2.0-84978066660 OR 2-s2.084995487750 OR 2-s2.0-84983757506 OR 2-s2.0-85000915457 OR 2-s2.0-84964933194 OR 2-s2.084979215078 OR 2-s2.0-84961204782 OR 2-s2.0-84973369496 OR 2-s2.0-84973523476 OR 2-s2.084918570568 OR 2-s2.0-84962617971 OR 2-s2.0-84958051790 OR 2-s2.0-85008477677 OR 2-s2.084953371205 OR 2-s2.0-84992159910 OR 2-s2.0-85045961049 OR 2-s2.0-84986270354 OR 2-s2.084953790779 OR 2-s2.0-84949743640 OR 2-s2.0-84949537928 OR 2-s2.0-84943551584 OR 2-s2.084941050028 OR 2-s2.0-84943578387 OR 2-s2.0-84939652758 OR 2-s2.0-84959217341 OR 2-s2.084960416222 OR 2 -s2.0-84919918859 OR 2 -s2.0-84926368446 OR 2 -s2.0-84930759973 OR 2 -s2.084945455745 OR 2-s2.0-84930399217 OR 2-s2.0-84928654413 OR 2-s2.0-85023631792 OR 2-s2.085007280708 OR 2-s2.0-84924525937 OR 2-s2.0-84932117266 OR 2-s2.0-84904293839 OR 2-s2.084906250125 OR 2-s2.0-84928949257 OR 2-s2.0-84906851364 OR 2-s2.0-85026258630 OR 2-s2.084885341936 OR 2 -s2.0-84888405047 OR 2-s2.0-84881023069 OR 2-s2.0-84881559891 OR 2-s2.084883181487 OR 2-s2.0-84879173918 OR 2-s2.0-84880624613 OR 2-s2.0-84878195752 OR 2-s2.084880155008 OR 2-s2.0-84955421530 OR 2-s2.0-84861835426 OR 2-s2.0-84870437251 OR 2-s2.084865843900 OR 2-s2.0-84858590776 OR 2-s2.0-84901333527 OR 2-s2.0-82655173686 OR 2-s2.084872030576 OR 2-s2.0-84865660076 OR 2-s2.0-80053080994 OR 2-s2.0-79960191840 OR 2-s2.084855933113 OR 2-s2.0-79955717350 OR 2-s2.0-84856500125 OR 2-s2.0-77954809333 OR 2-s2.077952189085 OR 2-s2.0-84857807358 OR 2-s2.0-70450209967 OR 2-s2.0-78649610603 OR 2-s2.070149115128 OR 2-s2.0-50849102639 OR 2-s2.0-36048986715 OR 2-s2.0-34748923479 OR 2-s2.034548404354 OR 2-s2.0-34347345892 OR 2-s2.0-33750607317 OR 2-s2.0-33947661387 OR 2-s2.076749110754 OR 2-s2.0-0037336037 OR 2-s2.0-0037337725 OR 2-s2.0-1642558461 OR 2-s2.00032848535 OR 2-s2.0-0030526113 OR 2-s2.0-84926281761 OR 2-s2.0-0018528428) 